\title{
Medically Underserved Community Integrative Health Education And Interprofessional Practice Model With First Year Physician Assistant, Physical Therapy, And Occupational Therapy Students
}

\section{Barbra Beck}

Carroll University

Karene Boos

Carroll University

Elizabeth Bright

Carroll University

Wendie Leveille

Carroll University

Amy Vega ( $\sim$ avega@carrollu.edu )

Carroll University https://orcid.org/0000-0003-1140-912X

Thomas E St. George

Carroll University

Barbara Ruggeri

Carroll University

Jane Hopp

Carroll University

Research article

Keywords: Integrative health, Interprofessional practice, Interprofessional education, Medically underserved community

Posted Date: October 16th, 2019

DOI: https://doi.org/10.21203/rs.2.16140/v1

License: (c) (1) This work is licensed under a Creative Commons Attribution 4.0 International License.

Read Full License 


\section{Abstract}

Background This study presents a unique combined approach to integrative health education and interprofessional practice in primary care with first-year health science graduate students.Methodology Physician assistant, physical therapy, and occupational therapy students participated in an integrative health interprofessional curriculum and collaborated with Hispanic seniors in a medically underserved community while working on interprofessional teams. Impact on students' knowledge and attitudes related to integrative health and interprofessional practice are assessed.Results Following exposure to the year-long curriculum, students demonstrated significant improvements in their knowledge of and attitudes towards integrative health and in their attitudes and perceived skills related to interprofessional practice.Conclusions Results suggest that the combined integrative health and interprofessional practice approach in a medically underserved community was successful in positively affecting related knowledge, attitudes, and skills. Further study related to longitudinal results is recommended.

\section{Background}

Population healthcare needs and healthcare delivery systems are evolving.

Healthcare practitioners must learn to respond to a rapidly aging population and an epidemiological shift from acute to chronic, degenerative diseases with a significant rise in non-communicable diseases influencing mortality and disability. ${ }^{1,2}$ Practitioners also face the challenge of a transition to a value based care delivery system with a focus on prevention and high quality outcomes. ${ }^{3}$ This is all in the shadow of a shortage of healthcare workers, especially within primary care. ${ }^{4}$ Ironically, however, it is the core principles of primary healthcare, which aim for "equitable and cost-effective population-health attainment," that can serve as a guide for health promotion to address these healthcare challenges. ${ }^{5} \mathrm{~A}$ response to this is to "incorporate integrative healthcare principles into primary care practice" ${ }^{6}$ and to implement an integrative healthcare delivery system through collaborative practice. ${ }^{6,7}$

Integrative health is a comprehensive approach to healing which relates to physical, emotional and spiritual health at an individual level. ${ }^{8,9}$ An integrated medicine and health approach to primary care "reaffirms the importance of the relationship between practitioner and patient, focuses on the whole person, is informed by evidence and makes use of all appropriate therapeutic approaches, healthcare professionals and disciplines to achieve optimal health." ${ }^{6}$ Integrative health can be used to "bridge the gap" between primary care, prevention and population health. ${ }^{8}$

In addition to an integrative health approach, there is a call for interprofessional collaborative practice to promote the delivery of effective, high quality care and to reduce costs. ${ }^{10}$ Patient healthcare needs are complex and challenging. It is well-understood that complex medical issues, patient-centered care and improved health outcomes can best be addressed through an interprofessional collaborative 
team approach. ${ }^{11}$ Interprofessional collaborative teams enable the sharing of expertise and perspectives with the goal to improve health outcomes and the patient experience. ${ }^{11,12}$ Interprofessional practice has been shown to provide a higher quality of care ${ }^{13-15}$ in an aging population with chronic disease and for maintenance of function. ${ }^{16,17}$ Educating future healthcare professionals to work within interprofessional teams has been recommended by numerous organizations in order to prepare students to be interprofessional practice-ready. ${ }^{18}$ "Interprofessional education is a collaborative approach to develop healthcare students as future interprofessional team members" ${ }^{11}$ and training programs are being implemented by educators in healthcare disciplines. ${ }^{18}$

In response to these trends, innovative curricular strategies need to be developed for the education of all disciplines of healthcare providers in the areas of both integrative health and interprofessional collaborative practice. Providing such training within the healthcare program curriculum will facilitate practitioner readiness to implement these practices at entry-level and assist students to understand the importance of this approach. This will result in improved health outcomes for patients. ${ }^{11}$ Curricular models can be didactic, simulation-based, experiential-based or a blend of these. $8,9,11$ Various models to prepare students across disciplines to demonstrate competency in integrative health and to operate with interprofessional collaboration have been reported separately, $8,9,11$ however our literature review found no established pedagogy on combining these two specific areas of training.

As part of a 5-year Health Resources and Services Administration (HRSA) Primary Care Training and Enhancement grant, the Carroll University (CU) College of Health Sciences grant team designed and implemented a training model to educate health professional students to prepare them to work in an interprofessional integrative healthcare delivery system. This model is a blend of didactic learning through an online integrative health curriculum coupled with an interprofessional practice experience providing primary care to geriatric clients in a medically underserved community. The training is completed under the supervision and guidance of $\mathrm{CU}$ faculty within the related programs. The purpose of this study was to investigate the effectiveness of this model as measured by student knowledge and attitudes about integrative health and interprofessional practice while working in a primary care, community-based interprofessional collaborative experience.

\section{Methodology}

Integrative Health Curriculum

CU graduate physician assistant (PA), physical therapy (PT), and occupational therapy (OT) students engaged in a 12-month integrative health $(\mathrm{IH})$ curriculum through completion of the "Foundations in Integrative Health" course, a 31.6-hour online curriculum from the National Center for Integrative Primary Healthcare (NCIPH). ${ }^{19}$ The NCIPH curriculum consists of six units which focus on the development of a core set of $\mathrm{IH}$ competencies and resources for healthcare providers in primary care. 
$\mathrm{NCIPH}$ unit titles and content summary can be found in Table 1. One hundred and twenty first-year graduate students (20 PA, 73 PT, and 27 OT) completed the "Foundations in Integrative Health" curriculum during their first professional year (three semesters - summer, fall, and spring).

Units 1-3 were assigned as part of the first semester (summer) of professional didactic courses for each program. ${ }^{20}$ The 73 PT students also completed unit 4 during the first semester. In the second semester (fall) of professional didactic courses, PA and OT students completed unit 4 and all students completed unit 5. The final unit of the NCIPH course, unit 6, was covered in the final semester (spring) of the first professional didactic year for each program. The curriculum was intentionally distributed across three semesters to prepare students for the concurrent interprofessional (IP) practice experience (Table 1) and was aligned with existing program material.

\section{Interprofessional Practice Experience}

Following the first semester (summer) of the integrative health curriculum, all 120 CU health sciences graduate students began a two-semester interprofessional case development experience with a senior client from a Hispanic community center in a medically underserved area using an $\mathrm{IH}$-focused case study template. The template, developed in collaboration with the University of Minnesota Center for Health IP Programs, is based on the IH framework and the social determinants of health, and provides a strategy for the IP team to gather information on their client's health and wellbeing, socioeconomic status, and physical environment, as well as other community-level data. ${ }^{21}$

Students were randomly placed in 15 interprofessional teams consisting of 7-8 students each (1-2 PA, 1-2 OT, and 4-5 PT) and remained with the same team for both semesters of the experience. Fifteen community-dwelling Hispanic seniors who participate in United Community Center (UCC) Senior Center activities were recruited for voluntary participation by UCC personnel during regular programming. CU Spanish program students were identified as interpreters to facilitate bilingual communication.

In the first semester of the experience (second semester of the year), the interprofessional teams and clients met biweekly face-to-face for 4-6 one-hour sessions to develop an IH case study about the UCC Hispanic senior client using the provided template. Each team also identified and outlined opportunities to enhance their client's health based on the social determinants of health. In the second semester of the experience (third semester of the year), student teams implemented an IP IH intervention with their Hispanic senior client based on their completed IP IH case study. Table 1 provides a visual outline of the integrative health curriculum, when it was offered to students, and how it relates to the concurrent IP experience.

Integrative Health Data Collection 
Students' integrative health knowledge and self-perceptions were assessed upon entrance to their program prior to curriculum access and following each semester of curriculum completion using two NCIPH knowledge and self-perception evaluations. ${ }^{19}$ The knowledge assessment reflects information presented in the six "Foundations in Integrative Health" units and consists of 30 multiple choice questions. The self-perception evaluation is a 35 -item tool which assesses confidence related to application of IH concepts in IP practice on a 5-point Likert scale (1 = strongly disagree, 5 = strongly agree). Pre-test evaluations were administered to all students prior to NCIPH curriculum enrollment and post-test evaluations were administered online at the end of each semester of the didactic year.

\section{Interprofessional Practice Experience Data Collection}

PA, PT and OT students' self-perceptions related to IP practice were gathered prior to the initiation of interprofessional activities and following each semester of the two-semester collaborative experience using two valid and reliable assessment tools. The Readiness for Interprofessional Learning Scale (RIPLS) assessed three areas of students' values of and attitudes toward IP learning on a 5-point scale (1 $=$ Strongly Disagree and 5 = Strongly Agree) ${ }^{22}$ The Interprofessional Collaborative Competencies Attainment Scale (ICCAS) was used to assess students' perceived skills and abilities in six domains on a 7-point scale ( 1 = Strongly Disagree and $7=$ Strongly Agree) ${ }^{23}$

\section{Data Analysis}

All quantitative data analysis was performed using the program $\mathrm{R}^{24}$ Comparison of pre-test and post-test data across the three disciplines was analyzed using Kruskall-Wallis, Welch's Anova, Dunn's Post-hoc, and Games-Howell tests. Differences from pre- to post-test scores between the three disciplines were analyzed using paired T-tests. Significant differences between groups was defined as $p=<0.05$.

\section{Results}

The 120 students were $23.0 \pm 2.6$ years old with $70.0 \%$ reporting as female. Ninety percent identified as Caucasian/non-Hispanic, 3.3\% as Caucasian and Hispanic, $4.2 \%$ as Asian, and $0.8 \%$ as two or more races, non-resident aliens or did not report a race/ethnicity.

As described above, two assessment tools evaluated students' integrated health $(\mathrm{IH})$ experiences (IH Knowledge Evaluation; IH Self Perception Evaluation) while one instrument evaluated their readiness for interprofessional practice (RIPLS) and another assessed students' perceived interprofessional practice skills (ICCAS). 
Results from all four assessments showed significant, positive change between pre-tests and final post-tests. Results are reported for combined responses from PA, PT, and OT students.

\section{$\underline{\text { IH Knowledge Evaluation Results }}$}

There is significant evidence to suggest students in the three disciplines demonstrated a considerable increase in $\mathrm{IH}$ knowledge scores from pre-test $(0.62 \pm 0.02)$ to post-test three $(0.74 \pm 0.02)$ for combined online units 1-6. However, progress between each of the four testing periods did not have as significant of evidence. While there was an increase between pre-test and post-test one $(0.66 \pm 0.02)$ scores, the increase was not significant. Compared to post-test one scores, post-test two $(0.66 \pm 0.02)$ scores slightly, but insignificantly, declined. Post-test three scores rebounded compared to post-test two scores, but the increase was not significant.

\section{$\underline{\text { IH Self-Perception Results }}$}

Similar to knowledge results, students in the three disciplines demonstrated a considerable increase in IH self-perception scores from pre-test $(2.52 \pm 0.10)$ to final post-test three $(3.41 \pm 0.10)$ with enough evidence to suggest the change is significant. However, unlike students' knowledge scores, there was a significant increase between pre-test and post-test one $(3.32 \pm 0.08)$ scores. This increase was followed by a slight dip in scores for post-test two $(3.26 \pm 0.09)$ compared to post-test one scores. As with the knowledge scores, students post-test three scores increased compared to post-test two scores, but not significantly.

\section{$\underline{\text { RIPLS Results }}$}

Unlike the IH self-assessment data, combined student responses for the three disciplines demonstrated significant evidence to suggest a decreasing change from pre-test $(4.16 \pm 0.07)$ to final post-test two $(3.99 \pm 0.10)$ in regards to attitudes towards IP. Additionally, there was significant evidence to support a decrease in attitudes between pre-test and post-test one $(4.02 \pm 0.09)$ scores.

\section{ICCAS Results}

Returning to the pattern from the $\mathrm{IH}$ assessment data, students' perceived interprofessional practice (IPP) skills demonstrated significant evidence to suggest considerable positive change from pretest $(5.02 \pm 0.16)$ to post-test one $(5.65 \pm 0.15)$, and from post-test one to post-test two $(5.70 \pm 0.19)$. 
Unlike results from the IH and RIPLS assessments, ICCAS scores did not decline between any of the three assessment points.

\section{Discussion}

In the complex and rapidly changing healthcare environment, there is a need for additional investigation into the best practice to prepare health sciences students to take an integrative approach to healthcare in an interprofessional model. Findings from this study could guide future preparation of students entering healthcare professions to be more practice-ready to employ skills in IH and IPP. The IH modules utilized were initially developed for primary-care residents, and have been further expanded to provide pertinent knowledge of $\mathrm{IH}$ to the interprofessional workforce ${ }^{25}$ as witnessed by the results of our study which included PA, PT and OT students. Our approach not only facilitates deeper learning by addressing cognitive, affective, and psychomotor domains, but allows IH and IPP to really "come alive" by providing experiential learning while building on teamwork and collaboration skills.

Results indicate that following an IP approach to integrative health in a combination of didactic and practice-based learning, students consistently showed improvement from pre-test to final post-test in areas including integrative health knowledge and self-perception along with perceived skills related to IPP. These findings are similar to those of other approaches including the University of Florida which implemented an IP approach to family care. ${ }^{26}$ Our approach differs from that at the University of Florida (UF) in: the health professions involved, in that our study brought allied health students onto the teams; meeting structure, with UF students conducting home visits; and clients, as clients in the University of Florida program range from young families to single elderly. ${ }^{26}$

A limitation of this study is the lack of performance measures, and as suggested by Chen and colleagues could be addressed by module implementation in curriculum followed by real-time feedback in a clinical setting from faculty or supervisors. ${ }^{27}$ First year health professions students have limited hands-on experience in clinical or practice settings. As a result, they may not have had the opportunity to see how IPP is managed in a "real world" practice environment, and thus they have not yet seen nor experienced the benefits of IPP. Furthermore, accuracy of readiness for IP learning is challenging to assess based on self-perception. The RIPLS asks students to determine their own readiness; however as novice practitioners they have not yet had the opportunity to fully understand the need for IPP. ${ }^{28}$ Nonetheless, over the course of the project students reported and demonstrated improvements in important skills and attitudes related to IPP, such as teamwork, collaboration, and conflict management. While the decrease in RIPLS scores was not ideal, new literature on the RIPLS scale suggests weakness in internal consistency and suggests that the lack of a sound IP theoretical framework at the time of tool development may be the cause. ${ }^{28}$

Our findings appear to be consistent with the theory of Mahler and colleagues that practice experience is necessary to foster an understanding toward IPP. ${ }^{28}$ The RIPLS data reflects that the greatest 
growth in students' attitudes and values toward the importance of IPP happened during the time they spent implementing an intervention with their client rather than during the time spent collecting data from clients and writing case studies. For this reason, future improvements would likely include earlier intervention implementation to allow students to get to the working phase of their relationships - both with the client and with the team.

\section{Conclusions}

These results suggest that a cross-cultural IP collaborative experience blending didactic and practice-based learning with an integrative approach may be an effective strategy for healthcare professional students to become better prepared to practice integrative health interprofessionally. However, for students to truly value and appreciate IPP they may need to see it implemented in a clinical or practice environment as practicing clinicians. A longitudinal study is recommended to determine if the positive results of this study are sustained once professionals enter the workforce.

\section{Abbreviations}

HRSA = Health Resources Services Administration

$\mathrm{CU}=$ Carroll University

PA = Physician Assistant

PT = Physical Therapy

OT = Occupational Therapy

$\mathrm{IH}=$ Integrative Health

$\mathrm{NCIPH}=$ National Center for Integrative Primary Healthcare

IP = Interprofessional

UCC $=$ United Community Center

RIPLS = Readiness for Interprofessional Learning Scale

ICCAS = Interprofessional Collaborative Competencies Attainment Survey

UF = University of Florida

IPP = Interprofessional Practice

\section{Declarations}




\section{Ethics Approval and Consent to Participate}

B1 exemption was granted by Western Institutional Review Board (WIRB) under WIRB Work Order \#1963419-1. As a result, the need for consent was waived by WIRB.

\section{Consent for Publication}

Not applicable.

\section{Availability of Data and Material}

The datasets used and/or analyzed during the current study are available from the corresponding author upon reasonable request.

\section{Competing Interests}

The authors declare that they have no competing interests.

\section{Funding}

This project is supported by the Health Resources and Services Administration (HRSA) of the U.S. Department of Health and Human Services (HHS) under grant number TOBHP29989 titled Primary Care Training and Enhancement. This information or content and conclusions are those of the author and should not be construed as the official position or policy of, nor should any endorsements be inferred by HRSA, HHS or the U.S. Government.

\section{Authors' Contributions}

All authors read and approved the final manuscript. BB wrote the results section and provided oversight in manuscript preparation. KB wrote the introduction section. EB and WL wrote the discussion and conclusion. AV wrote the methodology section. TESG analyzed and interpreted all quantitative data. BR coordinated the literature reviews for the introduction, discussion, and conclusion sections. JH provided oversight and editing throughout manuscript development. 
Acknowledgements

Not applicable

\section{Tables}

Table 1: Integrative Health Curriculum and the Relationship to Concurrent IP Experience 


\begin{tabular}{|c|c|c|c|c|}
\hline $\begin{array}{c}\text { NCIPH } \\
\text { Curriculum Unit }\end{array}$ & $\begin{array}{c}\text { Semester } \\
\text { Offered }\end{array}$ & $\begin{array}{l}\text { Hours to } \\
\text { Complete }\end{array}$ & Unit Content & Concurrent IP Experience \\
\hline $\begin{array}{l}\text { Unit 1: An } \\
\text { Introduction to } \\
\text { Interprofessional } \\
\text { Integrative Health in } \\
\text { Primary Care }\end{array}$ & $\begin{array}{c}\text { All - } \\
\text { Professional } \\
\text { Semester } 1\end{array}$ & $2 \mathrm{hrs}$ & $\begin{array}{l}\text { - Trends \& } \\
\text { challenges in US } \\
\text { health care } \\
\text { delivery } \\
\text { - Integrated } \\
\text { team approach }\end{array}$ & \multirow{3}{*}{$\begin{array}{l}\text { No IPP Experience (Professional Semester } \\
\text { 1) } \\
\text { Student completion of Units 1-3 prior to } \\
\text { the beginning of the IPP experience was } \\
\text { identified for establishment of a common } \\
\text { language among the three disciplines and } \\
\text { to prepare students for success during the } \\
\text { IPP experience. }\end{array}$} \\
\hline $\begin{array}{l}\text { Unit 2: Prevention } \\
\text { and Lifestyle } \\
\text { Behavior Change } \\
\text { Through } \\
\text { Interprofessional } \\
\text { Collaborative } \\
\text { Practice }\end{array}$ & $\begin{array}{c}\text { All - } \\
\text { Professional } \\
\text { Semester } 1\end{array}$ & $3.6 \mathrm{hrs}$ & $\begin{array}{l}\text { - Change theory } \\
\text { - Motivational } \\
\text { interviewing }\end{array}$ & \\
\hline $\begin{array}{l}\text { Unit 3: } \\
\text { Interprofessional } \\
\text { Healthcare } \\
\text { Wellbeing }\end{array}$ & $\begin{array}{c}\text { All - } \\
\text { Professional } \\
\text { Semester } 1\end{array}$ & $4.5 \mathrm{hrs}$ & $\begin{array}{l}\text { - Provider } \\
\text { wellness, } \\
\text { resiliency, } \\
\text { development } \\
\text { and burnout risk } \\
\text { - Wellness self- } \\
\text { assessment and } \\
\text { action plan } \\
\end{array}$ & \\
\hline $\begin{array}{l}\text { Unit 4: Addressing } \\
\text { Patients Through an } \\
\text { Interprofessional/ } \\
\text { Integrative Lens }\end{array}$ & $\begin{array}{c}\text { PT - } \\
\text { Professional } \\
\text { Semester } 1 \\
\text { PA \& OT - } \\
\text { Professional } \\
\text { Semester } 2\end{array}$ & $6 \mathrm{hrs}$ & $\begin{array}{l}\text { - Skills \& roles } \\
\text { of health } \\
\text { professionals } \\
\text { - Elements of } \\
\text { comprehensive } \\
\text { integrative } \\
\text { health history }\end{array}$ & $\begin{array}{c}\text { PT - No IPP Experience (Semester 1) } \\
\text { PA \& OT - IPP Experience - IP Case } \\
\text { Development (Semester 2) }\end{array}$ \\
\hline $\begin{array}{l}\text { Unit 5: Collaborative } \\
\text { Interprofessional } \\
\text { Integrative } \\
\text { Interventions }\end{array}$ & $\begin{array}{l}\text { All - } \\
\text { Professional } \\
\text { Semester } 2\end{array}$ & $6.35 \mathrm{hrs}$ & $\begin{array}{l}\text { - Development of } \\
\text { integrative plan } \\
\text { of care } \\
\text { - Application of } \\
\text { knowledge in } \\
\text { case scenarios }\end{array}$ & $\begin{array}{l}\text { IPP Experience - IP Case Development - } \\
\text { Semester } 2 \\
\text { Student completion of Units } 4-5 \text { was } \\
\text { assigned prior to or during the first } \\
\text { semester of the IPP experience with a } \\
\text { paired senior client from a Hispanic } \\
\text { community center in a medically- } \\
\text { underserved area as content is connected } \\
\text { to the IH-focused case study due at the end } \\
\text { of fall. }\end{array}$ \\
\hline $\begin{array}{l}\text { Unit 6: } \\
\text { Interprofessional } \\
\text { Practice in } \\
\text { Community Settings } \\
\text { and Systems at } \\
\text { Large }\end{array}$ & $\begin{array}{c}\text { All - } \\
\text { Professional } \\
\text { Semester } 3\end{array}$ & $6 \mathrm{hrs}$ & $\begin{array}{l}\text { - Traits of } \\
\text { effective } \\
\text { interprofessional } \\
\text { teams } \\
\text { - Best practices } \\
\text { for application } \\
\text { in community } \\
\text { and healthcare } \\
\text { systems }\end{array}$ & $\begin{array}{l}\text { IPP Experience - IP Case Implementation - } \\
\text { Semester } 3 \\
\text { Student completion of Unit } 6 \text { during the } \\
\text { second semester of the IPP experience } \\
\text { complemented the implementation of an } \\
\text { interprofessional integrative health } \\
\text { intervention with their senior client based } \\
\text { upon the completed case study from fall. }\end{array}$ \\
\hline
\end{tabular}




\section{References}

1. National Institute on Aging, National Institute on Health, United States Health and Human Services, World Health Organization. Global Health and Aging. [Washington]:NIH Publication no. 11-7737; 2011, p.9-10. http://www.who.int/ageing/publications/global_health.pdf. Accessed 21 Mar 2019.

2. Supper I, Catala O, Lustamn M, Chemla C, Bourgueil Y, Letrilliart L. Interprofessional collaboration in primary health care: a review of facilitators and barriers perceived by involved actors. J Public Health. 2015; 7(4):716-727.

3. Porter, ME. A strategy for health care reform- toward a value-based system. N Engl J Med.2009; 361(2):109-112.

4. Daly, R. Healthcare workforce shortage worsening: senators. Healthcare Financial Management Association. 22 May 2018. https://www.hfma.org/topics/news/2018/05/60811.html. Accessed 15 Nov 2018.

5. Demaio AR, Nielsen KK, Tersbøl BP, Kallestrup P, Meyrowitsch DW. Primary health care: A strategic framework for the prevention and control of chronic non-communicable disease. Glob Health Action. 2014;7: 24504.

6. Brooks AJ, Koithan MS, Lopez AM, et al. Incorporating integrative healthcare into interprofessional education: what do primary care training programs need? J Interprof Educ Pract. 2019;14:6-12.

7. World Health Organization. Framework for action on interprofessional education \& collaborative practice.[Internet]Geneva, Switzerland: World Health Organization; 2010.

https://www.who.int/hrh/resources/framework_action/en/. Accessed on 12 Dec 2018.

8. Jani AA, Trask J, Ali A. Integrative medicine in preventative medicine education: competency and curriculum development for preventive medicine and other specialty residency programs. Am J Prev Med 2015;49(5S3):S222-229.

9. Kligler B, Maizes V, Schachter S, et al. Core competencies in integrative medicine for medical school curricula: a proposal. Acad Med. 2004; 78(6):521-531. Accessed 20 February 2019.

10. Rosenburg K. Interprofessional collaborative practice model improves staff communication, patient care. Am J Nurs. 2018;118(3):70.

11. Bridges DR, Davidson RA, Odegard PS, Maki IV, Tomkowiak J. Interprofessional collaboration: three best practice models of interprofessional education. Med Educ Online. 2011;16:6035. 
12. Lumague $M$, Morgan A, Mak D, et al. Interprofessional education: the student perspective. J Interprof Care. 2008;20(3): 246-253.

13. Guraya SY, Barr $\mathrm{H}$. The effectiveness of interprofessional education in healthcare: a systematic review and meta-analysis. Kaohsiung J Med Sci. 2018;34(3):160-165.

14. Zanotti R, Sartor G, Canova C. Effectiveness of interprofessional education by on-field training for medical students, with a pre-post design. BMC Med Educ. 2015; 15:121.

15. Reeves S, Perrier L, Goldman J, Freeth D, Zwarenstein M. Interprofessional education: effects on professional practice and healthcare outcomes (update). Cochrane Database Syst Rev. 2013;3:CD002213.

16. Tsakitzidis $\mathrm{G}$, Timmermans $\mathrm{O}$, Callewaert $\mathrm{N}$, et al. Outcome indicators on interprofessional collaboration interventions for elderly. Int J Integr Care. 2016; 16(2):5.

17. Gougeon L, Johnson J, Morse H. Interprofessional collaboration in health care teams for the maintenance of community-dwelling seniors' health and well-being in Canada: a systematic review. J Interprof Educ Pract 2017;7:29-37.

18. Remington TL, Foulk MA, Williams BC. Evaluation of evidence for interprofessional education. Am J Pharm Educ. 2006;70(3):66.

19. National Center for Integrative Primary Healthcare. Foundations in integrative health. Updated 2018. https://nciph.org/curriculum.html. Accessed 25 Jul 2019.

20. North $S$, Beck B, Liveris $M$, et al. Students' knowledge and self-perceptions regarding integrative medicine and health following training in first-year graduate PA, PT and OT programs. J Allied Health. 2018; 47(3):e91-e95.

21. Uden D, Hess, LD. The case is clear: A guide to interprofessional case development.Minneapolis:MN: University of Minnesota Center for Health Interprofessional Programs(CHIP); 2016.

22. Parsell G, Bligh J. The development of a questionnaire to assess the readiness of health care students for interprofessional learning (RIPLS). Medical Educ.1999; 33(2):95-100.

23. Archibald D, Trumpower D, Macdonald C J. Validation of the interprofessional collaborative competency attainment survey (ICCAS). Interprof Care. 2014;28(6): 553-558.

24. R Development Core Team R: A Language and Environment for Statistical Computing. Vienna, Austria: the R Foundation for Statistical Computing; 2011. http://www.R-project.org/. Accessed 20 Apr 2019.

25. Kligler B, Brooks AJ, Maizes V, et al. Interprofessional Competencies in Integrative Primary Healthcare. Glob Adv Health Med. 2015;4(5):33-39.

26. Davidson RA, Waddell R. A Historical Overview of Interdisciplinary Family Health: A CommunityBased Interprofessional Health Professions Course. Acad Med. 2005;80(4):334-338.

27. Chen AK, Dennehy C, Fitzsimmons A, et al. Teaching interprofessional collaborative care skills using a blended learning approach. J Interprof Educ Pract. 2017; 8:86-90. 
28. Mahler C, Berger S, Reeves S. The readiness for interprofessional learning scale (RIPLS): A problematic evaluative scale for the interprofessional field. J Interprof Care.2015; 29(4): 289-291. 